\title{
MORPHOMETRIC STUDY OF PROXIMAL FEMUR AND ITS CORRELATION WITH BONE MINERAL DENSITY. A CROSS-SECTIONAL STUDY
}

\author{
LOPAMUDRA NAYAK, PRATIMA BAISAKH*, PRAFULLA KUMAR CHINARA \\ Department of Anatomy, IMS and SUM Hospital, Siksha 'O' Anusandhan Deemed to be University, K8, Kalinga Nagar, \\ Bhubaneswar - 751 003, Odisha, India. Email: drpbaisakh@gmail.com
}

Received: 30 April 2018, Revised and Accepted: 26 May 2018

\section{ABSTRACT}

Objective: Proximal femoral morphometries such as hip axis length (HAL), femoral neck (FN) axis length (FNAL), and FN shaft angle (FNSA) are important parameters for prediction of fracture risk. These parameters are affected by factors such as body habitus, age, sex, race, bone mineral density (BMD), and body mass index. Hence, the present study was designed to evaluate the relationship between proximal femoral morphometry and BMD.

Methods: We conducted an observational cross-sectional study in 168 patients. The measurements of radiological parameters such as HAL, FNAL, and FNSA were taken using dual-energy X-ray absorptiometry scan. FN-BMD was measured using LUNAR XR scanner and expressed as gm/cm². The correlation between proximal femoral morphometry and FN-BMD has been studied using Karl Pearson correlation coefficient (r).

Results: The mean age, height, weight, HAL, FNAL, FNSA, and FN-BMD of the study population were found to be 58.72 years, $160.15 \mathrm{~cm}, 64.38 \mathrm{~kg}$, $104.14 \mathrm{~mm}, 103.51 \mathrm{~mm}, 128.51^{\circ}$, and $0.761 \mathrm{~g} / \mathrm{cm}^{2}$, respectively. FN-BMD had a negative correlation with HAL ( $\mathrm{r}=-0.791$ ), FNAL ( $\mathrm{r}=-0.734$ ), and FNSA $(\mathrm{r}=-0.713)$ where $\mathrm{p}=0.000$.

Conclusion: There is a significant correlation between FN-BMD and proximal femoral morphometry. This observation will be helpful in exploration of its clinical significance in proximal femoral fracture.

Keywords: Femoral morphometry, Bone mineral density, Correlation.

(C) 2018 The Authors. Published by Innovare Academic Sciences Pvt Ltd. This is an open access article under the CC BY license (http://creativecommons. org/licenses/by/4. 0/) DOI: http://dx.doi.org/10.22159/ajpcr.2018.v11i8.26994

\section{INTRODUCTION}

The morphology of the proximal femur, specifically the relationships among the head, neck, and proximal shaft, has been a participant of interest and debate in literature dating back to at least the middle of the $19^{\text {th }}$ century [1]. Advanced age, female sex, osteoporosis, Caucasians, smoking, alcoholism, previous fracture, history of falls, and low estrogen level are the main risk factors for the occurrence of hip fractures. In the elderly, minor falls from the orthostatic position are responsible for approximately $90 \%$ of proximal femoral fractures. In young patients hip fractures are usually associated with high energy trauma [2]. The shape of the proximal femur is known to be an important risk factor for hip fracture of the femoral neck (FN), regardless of bone mass or bone strength [3]. A bone fractures when it is subjected to stresses greater than its ultimate strength. The stress within a bone depends on the geometric arrangement and the material of which the bone is made, as well as on the direction and size of the force applied [4]. Femoral morphometric parameters including hip axis length (HAL), FN axis length (FNAL), femoral head width, intertrochanteric width, and FN shaft angle (FNSA) have been related to the mechanical strength of the proximal femur. HAL, NSA, and FN width are important predictors of hip fracture both in men and women $[5,6]$. The risk of hip fracture can be predicted by some factors, such as body mass index (BMI), bone mineral density (BMD), the direction and severity of the fall, muscle strength, body habitus, femoral morphometry, and family history or lifestyle factors [7]. There are substantial variations in hip fracture incidence rates worldwide, which suggest the existence of important environmental factors that could be manipulated to reduce hip fracture occurrence. This substantial variation may be related to genetic factors and environmental conditions influencing BMI, BMD, and the morphometry of the proximal femur $[7,8]$. In this study, our aim was to obtain measurements of the proximal femoral morphometry and BMD and attempt to provide information about the correlation between morphometric indices of the proximal femur and BMD.

\section{METHODS}

The present study was an observational cross-sectional study carried out in 168 patients irrespective of sex, attending various outpatient department of a tertiary care hospital and coming to the Department of Radiology, Institute of Medical Sciences and SUM Hospital, Bhubaneswar. The participants were selected after a written informed consent was obtained from the patients. The study protocol was approved by our institutional ethics committee. Exclusion criteria include patients with a history of fracture due to osteoporosis, bilateral hip fracture, metabolic bone diseases, malignancy, renal failure, terminal illness, psychiatric illness, and severe dementia. Age, sex, height, and weight were measured for all the patients. Morphometric indices of the upper end of femur such as HAL, FNAL, and FNSA were measured by dualenergy X-ray absorptiometry (DEXA) scan and, FN-BMD was measured using LUNAR XR 1000 scanner and expressed as $\mathrm{g} / \mathrm{cm}^{2}$.

\section{Radiographic assessment}

The pelvic radiograms were taken with $15-30^{\circ}$ of internal rotation of the hips in the supine position. The beam centered in the symphysis pubis with a film focus distance of $100 \mathrm{~cm}$. For morphometric measurements, 15 inch $\times 12$ inch films were taken. One longitudinal line was drawn over the film, and few perpendicular lines $1 \mathrm{~cm}$ apart were drawn on that longitudinal line. The film was placed over that radiograms to facilitate accuracy and consistency of measurements and points of desired measurements were marked over lines. For all patients, skiagrams of left femur were taken for uniformity. Following parameters are being considered for all patients (Fig. 1). 


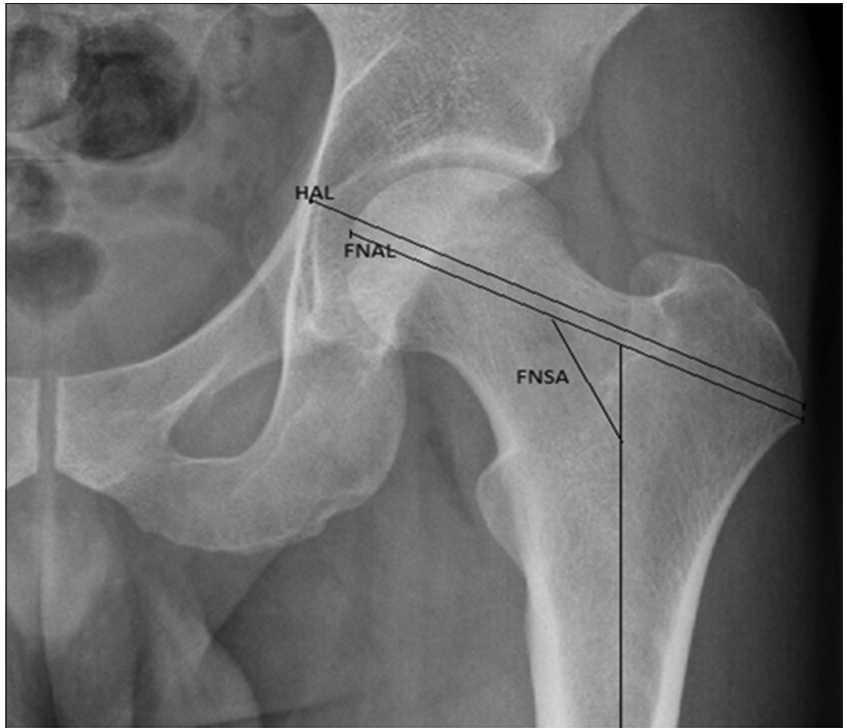

Fig. 1: Hip image shows different femoral neck measurements

Table 1: Average measurements of anthropometric and femoral morphometric parameters

\begin{tabular}{llll}
\hline Measurements & $\begin{array}{l}\text { Mean } \\
\text { value }(\mathbf{n = 1 6 8 )}\end{array}$ & SD & $\begin{array}{l}\text { Standard } \\
\text { error }\end{array}$ \\
\hline Age (year) & 58.72 & \pm 4.15 & 0.47 \\
Height (cm) & 160.15 & \pm 2.53 & 0.31 \\
Weight (kg) & 64.38 & \pm 6.35 & 0.33 \\
HAL (mm) & 104.14 & \pm 5.54 & 0.45 \\
FNAL (mm) & 103.51 & \pm 5.14 & 0.37 \\
FNSA (degree) & 128.51 & \pm 3.24 & 0.29 \\
FN-BMD (g/cm $\left.{ }^{2}\right)$ & 0.761 & \pm 0.153 & 0.31 \\
\hline
\end{tabular}

HAL: Hip axis length, FNAL: Femoral neck axis length, FNSA: Femoral neck-shaft angle, FN-BMD: Femoral neck bone mineral density, SD: Standard deviation

Table 2: Correlation between FN-BMD and proximal femoral morphometry

\begin{tabular}{llllll}
\hline & FN-BMD & HAL & FNAL & FNSA & p value \\
\hline FN-BMD & 1 & $-0.791^{* *}$ & $-0.734^{* *}$ & $-0.713^{* *}$ & 0.000 \\
HAL & & 1 & $0.867^{* *}$ & $0.870^{* *}$ & 0.000 \\
FNAL & & $0.823^{* *}$ & 1 & $0.883^{* *}$ & 0.000 \\
FNSA & & $0.831^{* *}$ & $0.852^{* *}$ & 1 & 0.000 \\
\hline
\end{tabular}

${ }^{* *}$ Correlation is significant at the level (2-tailed). HAL: Hip axis length,

FNAL: Femoral neck axis length, FNSA: Femoral neck-shaft angle,

FN-BMD: Femoral neck bone mineral density

- HAL in mm: From the base of the lateral part of the greater trochanter up to the inner pelvic brim

- $\quad$ FNAL in mm: Length from the lateral part of the greater trochanter up to the caput femoris.

- $\quad$ FNSA in degree: Angle between neck and shaft of femur.

The correlation of proximal femoral morphometry with BMD has been studied by using Karl Pearson correlation coefficient (r).

\section{RESULTS}

The mean values of all the parameters are shown in Table 1, and the correlation between FN-BMD and femoral morphometric parameters is represented in Table 2 . The mean age, height, weight, HAL, FNAL, FNSA, and FN-BMD of the study population were found to be 58.72 years, $160.15 \mathrm{~cm}, 64.38 \mathrm{~kg}, 104.14 \mathrm{~mm}, 103.51 \mathrm{~mm}, 128.51^{\circ}$, and $0.761 \mathrm{~g} / \mathrm{cm}^{2}$, respectively. The correlation between FN-BMD and proximal femoral morphometry is presented in Table 2. FN-BMD had a high degree of negative correlation with HAL ( $\mathrm{r}=-0.791, \mathrm{p}=0.000)$, with FNAL ( $\mathrm{r}=-0.734, \mathrm{p}=0.000)$, and also with FNSA ( $\mathrm{r}=-0.713, \mathrm{p}=0.000)$. Moreover, the femoral morphometric parameters were strongly correlated with each other (Table 2).

\section{DISCUSSION}

The present study reveals relationship between proximal femoral morphometry and BMD of FN in the study population. BMD is one of the most important determinants of skeletal strength. For each standard deviation reduction in bone mass, the risk of hip fracture increases by a factor of 1.5-3 [9]. BMD as measured by DEXA, particularly at the proximal femur, is the main determinant of the hip fracture risk $[10,11]$. On the other hand, a study by Faulkner et al. shows hip geometry is an indicator of hip fractures but is not influenced by age and BMD [12]. According to Prabhu et al., there is a negative correlation between femoral morphometry and BMD in south Indian population [13]. Similar type of relationship we found in our study on the eastern Indian population. This indicates decrease in BMD leads to increase in HAL, FNAL, and FNSA. On the contrary, Irdesel and Ari stated that there is a positive correlation between BMD and femoral morphometry in Turkish women [14]. This may be due to racial difference among study population. Iwamoto et al. also found a negative correlation between BMD and FNSA [15]. Low BMD is an important risk factor for hip fractures [10]. Low BMD is associated with decrease in bone mass which may affect morphometric changes in the upper end of femur and increase risk of fracture. Faulkner et al. quoted that BMD and HAL are significant independent predictors of hip fracture [16]. Brownbill et al. suggested that the longer HAL is negatively associated with FN BMD [17]. The decrease in BMD causes increase in proximal femoral morphometry, and this may be due to cortical thinning, age-related bone loss, and dietary habit which increases the risk of hip fracture. The variations in FNAL may be related to the higher occurrence of hip fracture [18-20]. The present study found negative correlation between FN-BMD and FNAL

\section{CONCLUSION}

The present cross-sectional study found significant correlation between BMD and proximal femoral morphometry and both should be taken into account for better prediction of fracture risk in an individual.

\section{AUTHOR'S CONTRIBUTION}

All the authors contributed equally.

\section{CONFLICTS OF INTEREST}

There are no conflicts of interest.

\section{REFERENCES}

1. Cooper AA. Treatise on Dislocations and Fractures of the Joints. $2^{\text {nd }}$ ed. Boston, MA: Lilly and Wait, Carter and Hendee; 1832.

2. Koval KJ, Zuckerman JD. Fraturas intertrocantéricas. In: Rockwood CA Jr., Green DP, Bucholz RW, editors. Rockwood E Green Fraturas Em Adultos. $5^{\text {th }}$ ed. Philadelphia, PA: JB Lippincott; 2006. p. $1635-80$.

3. Gregory JS, Testi D, Stewart A, Undrill PE, Reid DM, Aspden RM. A method for assessment of the shape of the proximal femur and its relationship to osteoporotic hip fracture. Osteoporos Int 2004;15:5-11.

4. Ravn P, Cizza G, Bjarnason NH, Thompson D, Daley M, Wasnich RD, et al. Low body mass index is an important risk factor for low bone mass and increased bone loss in early postmenopausal women. Early postmenopausal intervention cohort (ERIC) study group. J Bone Miner Res 1999; $14: 1622-7$

5. Alonso CG, Curiel MD, Carranza FH, Cano RP, Pérez AD. Femoral bone mineral density, neck-shaft angle and mean femoral neck width as predictors of hip fracture in men and women. Osteoporos Int 2000;11:714-20.

6. Bergot C, Bousson V, Meunier A, Laval-Jeantet M, Laredo JD. Hip fracture risk and proximal femur geometry from DXA scans. Osteoporos Int 2002;13:542-50. 
7. Glüer CC, Cummings SR, Pressman A, Li J, Glüer K, Faulkner Kg, et al. Prediction of hip fractures from pelvic radiographs: The study of osteoporotic fractures. The study of osteoporotic fractures research group. J Bone Miner Res 1994;9:671-7.

8. Gnudi S, Ripamonti C, Lisi L, Fini M, Giardino R, Giavaresi G. Proximal femur geometry to detect and distinguish femoral neck fractures from trochanteric fractures in postmenopausal women. Osteoporos Int 2002;13:69-73.

9. Marshall D, Johnell O, Wedel H. Meta-analysis of how well measures of bone mineral density predict occurrence of osteoporotic fractures. BMJ 1996;312:1254-9.

10. Cummings SR, Black DM, Nevitt MC. Bone density at various sites for prediction of hip fractures. The study of osteoporotic fractures research group. Lancet 1993;341:72-5.

11. Aloia JF, McGowan D, Erens E, Miele G. Hip fracture patients have generalized osteopenia with a preferential deficit in the femur. Osteoporos Int 1992;2:88-93

12. Faulkner KG, Cummings SR, Black D, Palermo L, Gluer CC, Genant HK. Simple measurements of femoral geometry predicts hip fracture: The study of osteoporotic fracture. J Bone Miner Res 1993;8:1211-7.

13. Prabhu K, Vathsala V, Mani R, Johnson WM. Correlation of anthropometric and upper femoral, morphometrics with osteoporotic related hip fracture risk. Int J Anat Sci 2010;1:1-6.

14. Irdesel J, Ari I. The relationship between the proximal femur morphometry and bone mineral density in Turkish women. Minerva Med 2006;97:153-9.

15. Iwamoto $\mathrm{N}$, Inaba $\mathrm{Y}$, Kobayashi $\mathrm{N}$, Ishida $\mathrm{T}$, Yukizawa $\mathrm{Y}$, Choe $\mathrm{H}$, et al. The Morphologic Factors Affecting the BMD of Proximal Femur in Hemi-Lateral Osteoarthritis of the Hip. Yokohama City University, Yokohama, Japan St Joseph's Hospital, Yokosuka, Japan. Poster no. 1363; ORS 2012

16. Faulkner KG, Wacker WK, Barden HS, Simonelli C, Burke PK, Ragi S, et al. Femur strength index predicts hip fracture independent of bone density and hip axis length. Osteoporos Int 2006;17:593-9.

17. Brownbill RA, Lindsey C, Crncevic-Orlic Z, Ilich Z. Dual hip bone mineral density in postmenopausal women: Geometry and effect of physical activity. Calcif Tissue Int 2003;73:217-24

18. Gnudi S, Ripamouti C, Gualtieri G, Malavolta N. Geometry of proximal femur in prediction of hip fracture in osteoporotic women. Br J Radiol 1999;72:729-33

19. Sulthana N, Vijaya K. Prevention of peptic ulcers by curcumin in chemically induced osteoarthritis. Int J Pharm Pharm Sci 2018;10:29-34.

20. Syngle T, Kaur S, Garg N. Osteoporotic fracture risk in rheumatoid arthritis. Int J Pharm Pharm Sci 2018;10:106-9. 